\title{
A Narrative on Students' Satisfaction in Fully Online and Modular Learning
}

\author{
Faye Joy F. Delos Reyes* \\ Dennis G. Caballes** \\ * Commonwealth High School, Department of Education \\ **Centro Escolar University, Philippines \\ DOI: 10.29322/IJSRP.12.01.2022.p12129 \\ http://dx.doi.org/10.29322/IJSRP.12.01.2022.p12129
}

\begin{abstract}
In the midst of the global health crisis brought about by COVID-19, the implementation of distance learning both online and modular has become the response of the educational sector. Due to the sudden occurrence of the pandemic, a lot of sectors were not able to prepare for it. However, for the continuity of education, different modalities have been identified and implemented. Even though online and modular distance learning grow more common in the education system, educators and institutions are still interested in knowing more about the factors that affect students' satisfaction. The educational material, platforms employed, teaching method, and accessibility all contribute to the students' contentment. The student's satisfaction of each modality has been proven to be effective in the teaching - learning process. The scores gathered during assessments serve as the indicator that the mode of instruction has been effective. In this study, it further assesses the level of satisfaction that the students have during online and modular distance learning. The result showed that the students using the modalities were content and satisfied with it. However, some noticeable improvements can be applied and done to further enhance the teaching and learning process. Some of these improvements were the inclusion of learning resources to accomplish tasks which seemed to be one of the things that should be given emphasis with, especially that the internet became the primary source of information for the students due to the prohibition of the government.
\end{abstract}

Index Terms- online learning, modular learning, students' satisfaction, instructional material

\section{INTRODUCTION}

Education must flourish and should not come to an end. Even when schools were not permitted to undertake face-to-face classes due to Covid - 19 pandemic over the past two years, students have received information through online and modular classes, which were created to help them continue their education. With all of the necessary changes with the academic processes, everyone was forced to adapt and embrace the new system. The Department of Education (DepEd) provided one of the solutions in DepEd Order No. 12 series 2020 [1], which streamlines the implementation of Most Essential Learning Competencies (MELCs) and prohibits face-to-face classes. The distribution of the MELCs is a component of the Bureau's long-term reaction, particularly during crises, as well as an answer to the contemporary pandemic's issues; thus, it can be developed as a way to assure curricular coherence in specific cases. Because we anticipated challenges in educational delivery, the MELCs would allow institutions and educators to focus on teaching some of the most essential and critical skills for the students to acquire. It will also facilitate the shift to digital learning processes by focusing on classroom-based learning technologies easier. It is suggested that in the present situation, several approaches and resources should be used.

The application of distance education was the approach of Higher Educational Institutions (HEIs) to continuous learning. Additional creative learning modalities were investigated urgently in order to facilitate the shift from the traditional to flexible teaching - learning options. These alternatives enabled for personalization of instructional strategies to satisfy students' demands for educational opportunities because students differ in relation to time, pace, and location [2]. In the formulation and construction of programs, lessons, and educational interventions, students' specific demands in terms of accessibility, duration, method, and outcomes of knowledge are explored. It included both online and non-digital technology, as well as face-to-face or in-person instruction, out-of-classroom learning, or a combination of these modes of delivery. When traditional teaching methods are inaccessible, such as in the occurrence of a national emergency, it assures the preservation of efficient and accessible education.

As the country transitioned to a new normal, everyone's ability to adapt was required. First and foremost, the school must be prepared for the form of instruction that will be used in the classroom. Second, the teachers' expertise and skills in the use of technology, as well as the development or usage of the instructional content must be ensured. Finally, the students' preparedness for the new normal must be emphasized. Due to this abrupt change, the researcher aims to assess the satisfaction of the students on the utilization of online and modular modes of instruction specifically on its implementation and technical skills needed for its success. 


\section{RESEARCH ELABORATION}

The government, along with all of its agencies, has not prepared for the virus's abrupt appearance. However, because of the requirement for consistency, online learning has become one of the options. One of the modalities that are being implemented was the online or virtual mode of instruction. Students that are kept separated from their professors while using a delivery mechanism is referred to as "virtual" or "distance" education. Technology mediates learner's engagement, and the structure of educational spaces (e.g., the physical space in which knowledge is acquired) could have a significant impact on the learning results. Effective online teaching requires rigorous instructional design and planning, which has been researched for decades. However, many students around the world were forced to switch from face-to-face training because of the COVID-19 pandemic [3]. In doing so, the schools conducted a lot of training that could be helpful for both the teacher and the students in their classes. Technology has become the key on how to make the teaching - learning effective. A lot of applications were discovered and adopted that suited the needs of both the teacher and students. When used correctly, technology will allow students and teachers to engage and collaborate with one another. The success of online learning is heavily dependent on the user's level of acceptance. Therefore, it is critical to examine the elements that influence how people utilize and embrace technology.

There are numerous technologies available for online learning, however they can sometimes cause significant problems. Downloading faults, installation issues, login issues, audio and visual problems, and so on are all examples of modern technological difficulties and problems. Online learning can be tedious and uninteresting at times [4]. As a result, the adoption of each school's chosen Learning Management System (LMS) developed a path for delivering lessons to students. However, technological issues continue to increase and the need to address these issues in order for the learning process to be effective becomes a must. Students must put what they've learned into practice for the educational process to be successful. Online content can sometimes be too theoretical, preventing students from properly practicing and applying concepts. This factor can be one of the dilemmas that both the teachers and students will experience because some topics and skills need to be done in actual classes to assess if a student has obtained mastery from it. However, in some studies, students tend to be unprepared to balance their work, family, and social lives with their academic activities in an online environment. They were also discovered to be underprepared for a variety of e-learning and academic-type abilities [5].

While the students appear to be ready to learn and eager to explore learning technology, their passions were deemed limited. Whether they are young adults or not, they want the teacher to be able to assist them with usability issues. Teaching will have to go further than just actual subjects and encourage them to learn and develop and explore a variety of topics. Teaching would have to go far beyond content knowledge and allow them to learn how to engage with technology and experiment with it. It implies that the use of technology should be integrated into an appropriate way of preparation between teachers and students. Whilst several studies have demonstrated that instructors' efficient implementation remains an important worry in a technology-enhanced classroom. This problem has been successfully addressed through guided preparation. The ideal strategy to balance the usage of technology by teachers and students will be determined by their readiness. Application utilization would provide realistic and engaging learning settings. Teachers should employ video games to simulate real-world situations in which students might apply new information and skills, perhaps leading to an increased grasp of higher-order mental notions and truths in many experiments [6]. The potential for new breakthroughs to encourage more inventive kinds of education is enormous. These changes in the teaching methodologies not only improve the nature of content learning but also the students' ideas and knowledge. It encourages intellectual abilities, analytical thinking, innovation, and other high-level talents among individuals. Technology can direct a variety of areas for advancement, improvements and innovation skills from students in the most effective way possible. The use of a technology platform to boost the students' enthusiasm and enhance expertise to the nature of the content is an element of the teaching - learning process. Students are also invited to pursue their ability to think critically to make it easier for them to understand their lessons. If they are exposed in their active learning, electronic databases will assist them in achieving excellent outcomes. Building a positive approach that conforms to the preferences of the students would pave the foundation for the expansion of online education. Individuals who place a high value on learning and have a strong desire to succeed might benefit from it. Comprehensive online courses are also more likely to help students who are proactive and dedicated.

Another mode of instruction implemented was the modular approach. When compared to traditional teaching methods, modular instruction is more effective in the teaching-learning technique since students begin at their own pace with this approach. It's an unconstrained self-learning program in which they are stimulated and their interest is piqued by quick feedback supplied to practice exercises. As a result, this type of learning modality promotes a student-centered approach. Teachers, students, and parents all faced issues as a result of the deployment of modular learning. According to a study, the key obstacles were a lack of government money in the design and distribution of modules, students' struggles with self-study, and parents' lack of understanding in academically guiding their child/children. It is clear that using modular distance learning comes with its own set of challenges [7]. Due to public health concerns, merging Self Learning Modules (SLMs) with other learning delivery modalities (modular, television-based, radio-based teaching, mixed, and online) would ensure that all children have access to a high-quality basic education. Equipment, financing, and resources become one of the issues that must be handled as a result of the quick adoption of modular distance learning. This type of method was developed to help students who are unable to participate in online classes owing to a lack of access, gadgets, or an unreliable internet connection. Worksheets and learning materials based on print became the key to promoting learning. Teachers can use worksheets as an assessment tool to understand students' previous knowledge, learning goals, and learning activities, and students can 
use them to measure their own cognitive development. [8]. One form of material that might be used is the Learner Activity Sheet (LAS) (worksheet). The worksheet will be beneficial to both teachers and students. Using this resource, the teacher evaluates the student's knowledge. This would be utilized not as a kind of evaluation, but rather as a method of interaction between both the teacher and the student. The purpose of LAS is to allow students to have an active role in the process by supporting them in creating and finding notions through science process skills, as well as to serve as a reference for teaching and learning throughout the education process. It could have been used as a leap instruction manual for experiments, demonstrations, and discussions.

The ultimate consequence of any educational institute's performance is satisfaction. Any individual's adoration is piqued by the desired consequence of any goal. Students' satisfaction is a result of positive relationships with their teacher. Significant opportunities boost students' performance without sacrificing teaching quality and course material. Performance is defined as the culmination of studentteacher endeavors, and is demonstrated in the students' engagement in every class or session. The academic success of the students is a fundamental component of learning. As a result, it is seen as the primary point, as well as the overall educational system outcome [9]. Because educational materials can be altered and generated by teachers, students' interest in learning can be increased. It can ensure that the teaching - learning process will be successful in this approach. Educators are encouraged to develop a wide range of teaching materials so that students' understanding will not become regular nor boring.

Students' satisfaction for both online and modular approaches should be assessed to determine the effectiveness of each modality. The ideal conclusion of any goal that enriches someone's admiration is satisfaction. If the students feel the satisfaction of the delivery of learning, positive feedback follows. Encouragement and rapport between the students and the teachers are established, bringing about a healthy teaching-learning relationship. Successful outcomes boost student satisfaction by improving teaching quality and course material. Student satisfaction is measured in terms of motivation, learning, assurance, and retention. According to several studies, performance is the culmination of student-teacher efforts, and demonstration of students' interest in the courses. The academic achievement of the learner is a crucial aspect of education, hence, an improved and effective system of delivery should be employed to achieve this satisfactory feedback from the students. It was found that the quality of education impacts the successes and failures of educational institutions [10]. Student satisfaction was determined solely on the basis of each student's academic achievement. If the students were able to achieve high results throughout the assessment, the teaching - learning process, comprising the resource materials, contents, and execution, was effective. In distant education, evaluation is crucial, and it has several characteristics that fit with the goals of a course or program. In online learning, course grades are frequently employed as a measure of student achievement. However, in online environments, affective aspects might be just as essential as cognitive factors in explaining and predicting student learning. Student satisfaction is one of the most important factors that influence the quality of online programs at higher education institutions. Online students' viewpoints provide useful information on topics of interest to a student, as well as assisting institutions in good perspective their capabilities and difficulties in providing online courses. These assessments should not only be done to online students but also employed to the modular print - based students. It is vital to determine how the worksheets and modules used could be effective for learning. Using this, the school and the teachers can have the chance to develop, modify or remove some topics which could be difficult or irrelevant to the subject matter.

As part of the educational system continuity plan, students can choose online distance or modular distance learning in the current situation. The researcher designed three distinct research questions in the study:

1. What are the students' perceptions on online and modular distance learning?

2. What are the students' level of satisfaction on online and modular distance learning in terms of:

a. Implementation

b. Technical Skills

3. What are the students' feedback on online and modular distance learning?

A descriptive thematic approach was used in the study. It caters 30 students who were enrolled in one of the tertiary schools in Quezon City. All of the respondents in the study will be 3rd year Criminology students for the First semester of Academic year $2021-2022$. Furthermore, an informed consent was secured to the students to assure that the data collected will be kept for data analysis only. In measuring the satisfaction of each modality, the researcher adopts a standardized questionnaire from the National Assessment and Accreditation Council (NAAC), Student Satisfaction Survey under Criterion II of Teaching - Learning and Evaluation. This survey evaluates both the implementation and the technical requirements needed both for the online and modular approach. Moreover, the survey form used a rating scale of 0 to 4 which was qualitatively interpreted as poor (0), fair (1), good (2), very good (3) and excellent (4). However, the researcher has modified some of the questions to fit the survey with the research questions.

Due to the inability to conduct face to face gathering of data, the researcher used Google form for the data collection. The research instrument used by the researcher was made of three parts. The first part was the profile of the students and a narrative question on their perception about online or modular distance learning. This part aims to determine the number of respondents who were on online or modular mode of instruction and their views and opinions of the mode of instruction. The second part of the instrument was the rating scale that aims to measure the satisfaction of the respondents on each modality. The last part of the instrument was a narrative question 
that wants to find out the students' feedback for an online and modular approach. The research instrument was first validated and underwent reliability testing with a result of 0.879 for the Cronbach's Alpha for 20 item questions. The qualitative data that were collected was analyzed using the SPSS ver. 23 statistical software. Specific remarks on the perception, student satisfaction and feedback will be determined using descriptive analyses. A statistical mean and standard deviation will be employed to each question to assess how the students perceived each modality.

\section{RESULT FINDINGS}

\section{A. Perception of Online and Modular Distance Learning}

The existing modalities allowed by the DepEd on the selected school was online distance learning and modular distance learning. The results showed that most of the respondents preferred to have online distance learning with a frequency 19 (63.33\%) while 11 (36.67\%) opted to have modular distance learning. Some of the noted perceptions of the students about online distance learning was that it utilizes technology, virtual discussions and online assessments. However, in modular distance learning, students perceive that the print - based modules, activity sheets will be used. The same perception on following the due dates for submission and tasks were being implied. The result showed that they have the same ideas about online and modular distance learning in terms of following instructions and to be self - directed on their learning. The orientation conducted before the start of the school year helps them to evaluate their capabilities to adapt with these changes. With the help coming from their parents and guardians, the students were able to decide which modality they will use for the school year. One of the skills that both the online and modular distance learning students should acquire was the use of Self - Directed Learning (SDL). SDL is defined as a process in which individuals, with or without the assistance of others, diagnose their own learning requirements, set learning goals, identify human and material resources for learning, select and apply effective learning strategies, and evaluate learning outcomes [11]. Simultaneously, a self-directed learning environment appears to be capable of improving one's life. This method of instruction will motivate students to study more and accomplish their best. It will also help children build judgment abilities as early as puberty, which will help them in the future. The quality of teaching and learning can improve if the learning environment enables for self-directed learning. Appropriate interventions, preparation, monitoring, and execution of the learning environment must be carefully studied and a schemed platform where teachers can grow their skills and competences should be required in their professional development for a beneficial and long-term use.

\section{B. Satisfaction Level for Online Distance Learning}

Descriptive analyses on the students' satisfaction level for online distance learning have been computed with a statistical mean of 3.056 and with a qualitative interpretation of very good. As a result, students who choose online distance learning were satisfied with the delivery and information used during synchronous and asynchronous sessions, according to the findings. This shows that the platform, notably the Learning Management System and Facebook Messenger, meets the students' expectations. The use of these platforms allows students to become more productive because they are simple to use. According to several studies, Facebook will increase access to knowledge and learning possibilities. Surveys have shown a significant increase in students' performance as measured by pre- and posttest grades, indicating that it is a viable instructional strategy. This is a means of encouraging students to interact with the technologies they are already familiar with [12]. It has been established that Facebook is the most convenient way for students to access information. Because it only requires minimum preparation for both the teachers and the students, it allows teachers to provide instructions to all of the students. Furthermore, the delivery of online instruction by the teachers was well - prepared. On conducting online classes, teachers were also required to prepare instructional materials that can be used as a reference during synchronous sessions. As the students present their thoughts in class, students should be given clear directions to produce an output that is linked with the topic of conversation. It's crucial to keep students in different places in touch with the teacher, and the support personnel. Notably, aside from the instructional materials, some simulations, games and interactive models can be utilized to let the students gain mastery from the topic just by using some online application.

\section{Satisfaction Level for Modular Distance Learning}

The statistical mean of 3.461 (very good) on the level of satisfaction of students for modular distance learning can be concluded to be effective. Students were able to appreciate the information in a creative way because of the well-designed worksheets. Worksheets have been shown to be an excellent teaching tool. Worksheets can help students stay engaged and retain material by encouraging active participation and exhibiting cognitive ability [13]. A component of the teaching - learning process is the use of a variety of instructional resources to increase students' enthusiasm and competency in the particular topic. Students are also encouraged to use their analytical skills to help them understand their subjects more easily. As the students criticized the activity sheets, the choice of words was emphasized. This result can be sufficient to show that the words, pictures and arrangement of each worksheet should be taught by the teacher. This element was important for the facilitation of learning to the students because most of them do not have any source to accommodate online learning. The technical skills in writing modules of the teachers should be assessed, too, to ensure that the students could gain knowledge from the modules and activity sheets. Expertise of the module writers were required to guarantee that correct information was passed to the students.

\section{Feedback for Online and Modular Distance Learning}

Some of the feedback identified by the students for both online and modular distance learning were the supplemental resources that could be used to answer the task. Due to accessibility of the internet, a lot of information can be acquired from it. However, the reliability 
of each source remains questionable. The students' capabilities to assess each resource was insufficient that will eventually lead to misconceptions and false information. In today's school system, internet research and inquiry projects are very popular. Even when undertakings are not officially given as an internet-based research task, a majority of secondary school students and undergraduates report using the web as their main source for their classwork. Fewer and fewer people go to the library to read real books. Even published sources (journal articles) are increasingly being accessible electronically [14]. In addition, with the pandemic, the students were limited to stay at home and use the web on answering their assignments. And because of this, teachers need to teach the students on how to determine the appropriate material for each topic.

\section{REFERENCES}

[1] DepEd Order No. 12 Series 2020 “Adoption of the Basic Education Learning Continuity Plan for School Year 2020 - 2021 in light of the Covid - 19 Public Health Emergency". Department of Education. https://www.deped.gov.ph/wpcontent/uploads/2020/06/DO_s2020_012.pdf

[2] CMO No. 4 Series 2020 "Guidelines on the Implementation of Flexible Learning”. Commission of Higher Education. https://ched.gov.ph/wp-content/uploads/CMONo.-4-s.-2020-Guidelines-on-the-Implementation-of-Flexible-Learning.pdf

[3] A. Hermida, "College students Use and Acceptance of Emergency Online Learning Due to COVID - 19": International Journal of Educational Research Open 1 (2020) 100011

[4] S. Dhawan, "Online Learning: A Panacea in the Time of COVID - 19 Crisis". 2020. Journal of Educational Technology Systems. Volume 49 (1) 5 - 22

[5] L. Schindler, G. Burkholder, O. Morad, C. Marsh, "Computer - Based Technology and Student Engagement: A Critical Review of Literature". 2017. International Journal of technology in Higher Education. DOI 10.1186/s41239-017-0063-0

[6] L. Pedro, C. Barbosa, C. Santos, "A Critical Review of Mobile Learning Integration in Formal Educational Context". 2018. International Journal of Educational Technology in Higher Education. DOI 10.1186/s41239-018-0091-4

[7] F. Castroverde, M. Acala, "Modular Distance Learning Modality: Challenges of Teachers in Teaching Amid the COVID - 19 Pandemic". 2021. International Journal of Research Studies in Education. 2021. Volume 10, Number 8, 7 - 15.

[8] M. Siahaan, M. Sirait, "Development of Student Activity Sheet (Worksheet) Based on Guided Inquiry to Improve Student's Critical Thinking Skills in Senior High School". 2017. Journal of Education and Practice, Volume 8, Number 20. ISSN: $2222-288 \mathrm{X}$

[9] O. Effiong, C. Igiri, "Impact of Instructional Materials in Teaching and Learning of Biology in Senior Secondary Schools in Yakurr LG A.", 2015. International Letters of Social and Humanistic Sciences, Volume 62, pp. 27 - 33. ISSN: $2300-2697$

[10] R. Gopal, V. Singh, A. Aggarwal, "Impact of Online Classes on the Satisfaction and Performance of Students During the Pandemic Period of COVID - 19". 2021. Education and Information Technologies. https://doi.org/10.1007/s10639-021-10523-1

[11] J. Robinson, A. Persky, "Developing Self - Directed Students". 2020. American Journal of Pharmaceutical Education. Volume 84 (3), Article 847512

[12] N. Jumaat, Z. Tasir, "Facebook as a Platform for Academic - Related Discussion and Its Impact on Students' Success". 2016. Fourth International Conference on Information and Communication Technologies (ICoICT)

[13] V. Monding, J. Buniel, "Effectiveness of Developed Worksheets to the Academic Achievement of Students in Science 9 Concepts", 2021. International Journal for Innovation Education and Research. ISSN: $2411-2933$

[14] C. Sanchez, J. Wiley, S. Goldman, "Teaching Students to Evaluate Source Reliability during Internet Research Tasks". 2006

\section{AUTHORS}

First Author - Faye Joy F. Delos Reyes, Teacher 1, Commonwealth High School, delosreyes1902690@ceu.edu.ph

Secondary Author - Dennis G. Caballes De La Salle-College of Saint Benilde, dennis.caballes@ benilde.edu.ph

Corresponding Author - Faye Joy F. Delos Reyes, Teacher 1. Commonwealth High School, fayedr29@gmail.com, +639472683431 